\title{
Safety Analysis of Barge Maneuvers in Restricted Port Area
}

\author{
I Putu Sindhu Asmara ${ }^{1,2, a, *}$, Kriyo Sambodho ${ }^{2,3, b}$, A.A.B. Dinariyana ${ }^{2,4, c}$, and Ketut Buda \\ Artana $^{2,4, d}$ \\ ${ }^{1}$ Department of Shipbuilding Engineering, Politeknik Perkapalan Negeri Surabaya, S urabaya, \\ Indonesia \\ ${ }^{2}$ PUI Keselamatan Kapal dan Instalasi Laut,Surabaya, Indonesia \\ ${ }^{3}$ Department of Ocean Engineering, Institut Teknologi Sepuluh Nopember, Surabaya, Indonesia \\ ${ }^{4}$ Department of Ocean Engineering, Institut Teknologi Sepuluh Nopember, Surabaya, Indonesia \\ a.ptsindhu@gmail.com,b.dhodhott@yahoo.com,c.kojex@its.ac.id,d.ketutbuda@its.ac.id \\ *corresponding author
}

Keywords: $\quad$ MMG Model, Safety Index, Collision Probability, Tugboats, Port Area.

Abstract: This paper provides a case study on manoeuvring safety analysis of barge in a restricted area. A developing port is intended to handle barge having the capacity of 10.000 DWT. The port basin is enclosed by wharf and jetty belonging to two companies. A halflength of the new wharf is blocked by the existing jetty. The jetty located at entrance of wharf basin has a possibility to be crashed by the barge. This research is aimed to analyse the safety index and collision probability of the barge at the area. Maneuvering simulation is developed by using Mathematical Maneuvering Group (MMG) model to determine the number and capacity of required tugboats. The safety index is calculated based on Environment Stress method and the probability of collision is analysed using the predicted path of the barge. The result of simulation shows that manoeuvres are at a critical condition of safety index and required tugs capacity is higher than the requirement of the authority.

\section{Introduction}

Development of a port area requires coordination and cooperation between companies, especially for those having a limited access to the coastal area. New jetties should be design in such a way that the maneuvering of berthing and unberthing in the new jetties can be performed safely and the maneuvering near to the existing jetties has an acceptable risk. This paper provides a study on maneuvering safety in coastal area occupied by a petrochemical and a smelter and refinary companies located in the West Surabaya Channel. This study is intended to provide procedure of tugboats assisting ships or barges for berthing and unberthing manuever. The procedure should be implemented by pilot, captain, and tug masters as the measure to decrease the number of collision in the area. In the early of January 2018 MV Action Trader, a bulk carrier with the capacity of 39,300 DWT attack the mooring dolphin of jetty of the petrochemical terminal. The structure of mooring dolphin was sinking and the ship was stranding. The ship has been evacuated by four tugboats at the condition of high tide [1]. The positions of broken mooring dolphin and the development of new 
wharf of the petrochemical company as well as the existing jetty of the smelter company in the research area is shown in Figure 1.

Training on harbour towage operations is very important for tug masters to gain competence and confidence, especially for a new developing port area. In this study, the path of barge towage is simulated using the Mathematical Manoeuvring Group (MMG) model. The predicted path is analysed to calculate degree of difficulty of the towing manoeuvre and collision probability using Environment Stress and geometrical methods, respectively.

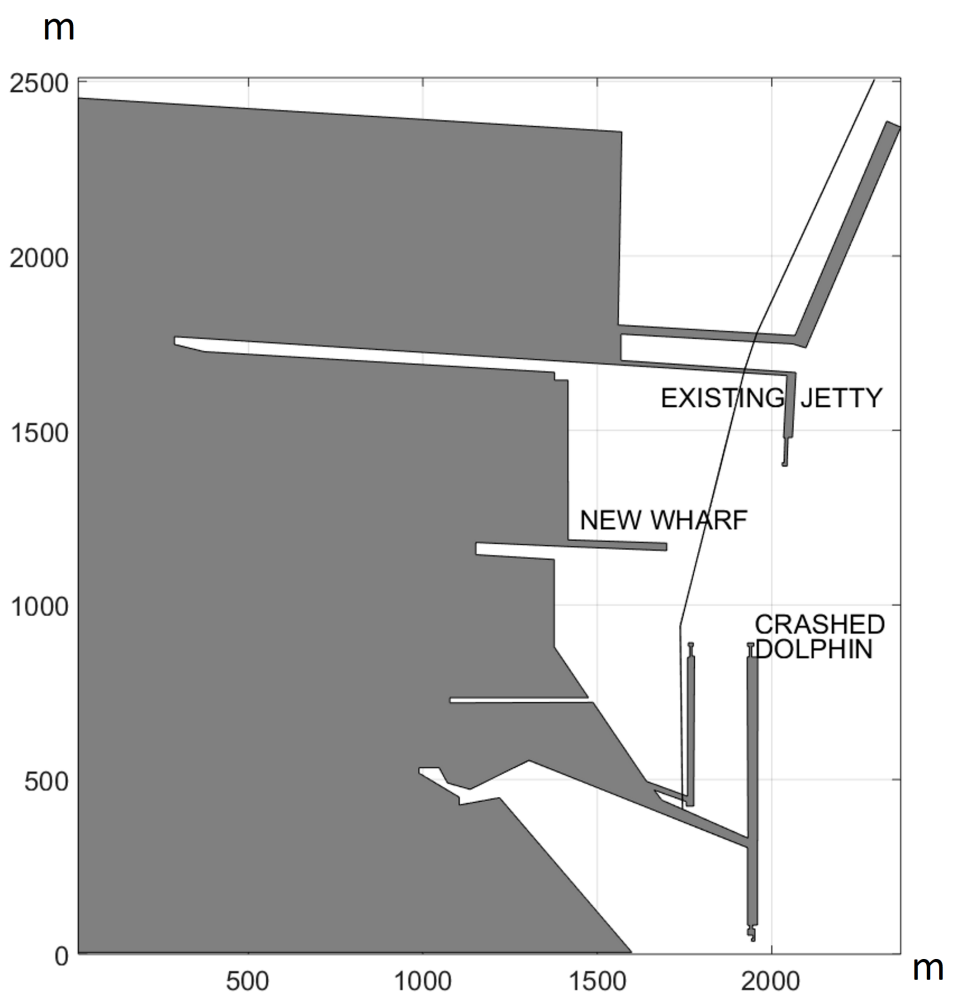

Figure 1: Area of study.

The aims of this study are:

1) To determine the number and capacity of tugs to assist berthing-unberthing manoeuvre of barge at any position of the wharf,

2) To evaluate the degree of difficulty of tugs to assist the manoeuvres, and

3) To determine the probability of collision in the research area.

\section{Method}

\subsection{The MMG Model}

The model consists of three motions including surging, swaying, and yawing as expressed in (1), (2), and (3), respectively $[2,3]$.

$$
\begin{aligned}
& \text { Surge: }\left(m+m_{x}\right) \dot{u}_{G}-\left(m+m_{y}\right) v_{G} r_{G}=X_{H}+X_{E}+X_{T} \\
& \text { Sway: }\left(m+m_{y}\right) \dot{v}_{G}+\left(m+m_{x}\right) u_{G} r_{G}=Y_{H}+Y_{E}+Y_{T} \\
& \text { Yaw: }\left(I_{z z}+J_{z z}\right) \dot{r_{G}}=\left(N_{H}+N_{E}+N_{T}\right)-x_{G}\left(Y_{H}+Y_{E}+Y_{T}\right)
\end{aligned}
$$


where

H subscript represents the hull forces and moment

E subscript represents environment forces and moment

T subscript represents the tug forces and moment

The current effect is calculated based on the relative velocity with respect to the moving frame. The effects of wind on manoeuvring are calculated in the MMG model based on Fujiwara's estimation of wind forces and moment [4].

Two coordinate systems of body fixed and space fixed are involved in the model. The centre of space fixed coordinate is determined in a certain position of the port map, $\mathrm{O}$ and the body fixed coordinate system is the centre of gravity of the ship, G. The coordinate system of MMG model is shown in Fig. 2. The ship course is represented by the direction of ship's speed, U and heading of ship is represented by $\psi$.

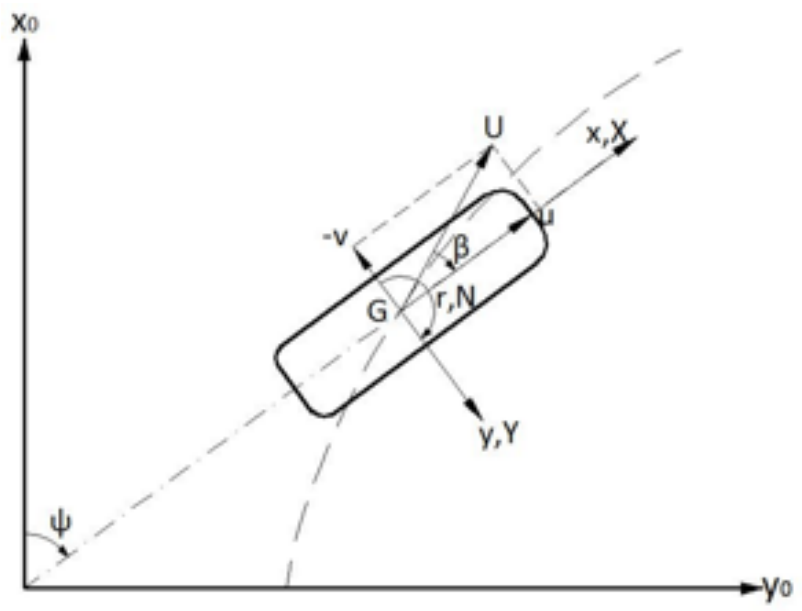

Figure 1: Coordinate system of MMG model.

\subsection{Environment Stress}

The ES is used for the assessment of navigator difficulties for steering ship movement in a port area $[5,6]$. The method considers the ship-human-environment factors and uses a questionnaire to obtain the navigators' perception on multiple situations of ship courses within 180o in the restricted area. The subjective judgment of the navigators is formulated in a regression equation for the estimation of the ES.

The ES method is implemented by simulating the ship courses between $-90^{\circ}$ and $90^{\circ}$ from the current ship course along the ship's path. Subjective judgments based on topographical obstacles (SJL) and traffic obstacles (SJS) are made according to the equations proposed by Inoue et al. [5]. The ES is calculated based on (4) and (5).

where:

$$
S J_{L}=\alpha(R / V)+\beta
$$

$\alpha=-0.00092 \log _{10}(G T)+0.0099$, for $G T \leq 10,000 G T$,

$\alpha=0.006671 \exp \left(-7 \times 10^{-6}(G T)\right)$, for $G T>10,000 G T$,

$\beta=-3.82$, GT is the gross tonnage of the ship, $R$ is the distance to a topographical obstacle, and $\mathrm{V}$ is the ship speed.

where:

$$
S J_{S}=\alpha\left(R / L_{m}\right)+\beta
$$


$\alpha=0.0019 \mathrm{Lm}$,

for ships from star board $\quad: \beta=-0.65 \ln (\mathrm{Lm})-2.07$,

for ships from port side $\quad: \beta=-0.65 \ln (\mathrm{Lm})-2.35$,

for head on condition $\quad: \beta=-0.65 \ln (\mathrm{Lm})-2.07$,

for overtaking condition $\quad: \beta=-0.65 \ln (\mathrm{Lm})-0.85$,

$L m$ is the average length between the subject ship and a target ship, and $R$ is distance between the ships.

The course over ground (COG) is simulated to change between $-90^{\circ}$ and $90^{\circ}$ from the actual COG. The ES is a summary of the aggregate subject judgments, the SJL and SJS values, for all ship courses in the $180^{\circ}$ range, as expressed by (6).

where:

$$
E S=\sum_{j} S J_{L j}+\sum_{j} S J_{S j}
$$

$\mathrm{j}=$ the ship course from $\mathrm{COG}-90^{\circ}$ to $\mathrm{COG}+90^{\circ}$.

The indices of SJ, which are distributed from 3 to -3 and estimated using the regression equation, are converted into the ES index from 0 to 6 . The maximum aggregate value of the ES index is six multiplied by the $180^{\circ}$ directions. The values of ES fall between zero for extremely safe and 1000 for extremely dangerous.

\subsection{Collision Probability}

The probability of ship to collide the new jetty is calculated based on (7) and the probability of ship attack the under water gas pipe line is calculated based on (8):

where:

$$
P_{C J}=P_{C G} \times P_{C A}
$$

$\mathrm{P}_{\mathrm{CJ}}=$ probability of ship to collide the new jetty

$\mathrm{P}_{\mathrm{CG}}=$ geometrical probability $=\mathrm{B} / \mathrm{B}_{\mathrm{G}}$

$\mathrm{B}=$ projected ships' dimension in maneuvering area

$\mathrm{B}_{\mathrm{G}}=$ the width of maneuvering area

$\mathrm{P}_{\mathrm{CA}}=$ causation probability of failing to avoid collision

$=1.08 \times 10^{-4}[7]$

$$
P_{C P}=2 L / L_{G} \times P_{C J} \times P_{S C}
$$

where:

$\mathrm{P}_{\mathrm{CP}}=$ probability of ship to attack the underwater pipe line

$\mathrm{P}_{\mathrm{SC}}=$ probability of ship sinking after a collision accident in the area $=0,34$ [7]

$\mathrm{L}=$ average ship length $=100 \mathrm{~m}$

$\mathrm{L}_{\mathrm{G}}=$ path length at the basin

The flow of study on maneuvering safety in a restricted port area is shown by Figure 3 


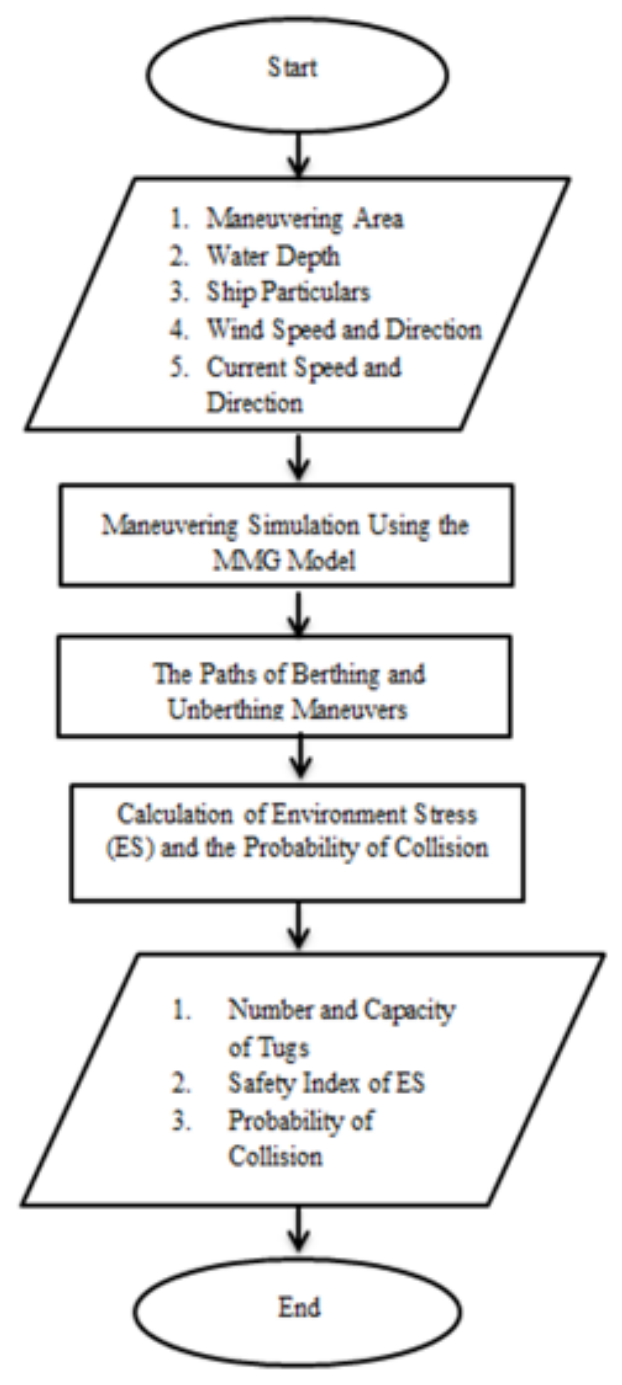

Figure 3: Flow chart of the study.

\section{Results}

A barge with the capacity of 10,000 DWT is selected as the subject ship as the case study. The dimension of the barge is shown in Table $\mathrm{I}$. The depth of water at the basin is 8.3 meter $(\mathrm{m})$, current speed is 0.82 meter per second $(\mathrm{m} / \mathrm{s})$ to the East, and the wind is from the West with the speed of 10.8 knots (kts).

Three position of berthing and unberthing are simulated for the schenarios of meneuvering. The maneuvering consists of towing and escorting maneuvers as shown in Fig. 4 and lateral movement as shown in Fig. 5. The figures show two barges have already been berthed at the wharf. The third barge has very limited area for the berthing maneuver. The third barge entering the wharf is shown in Figure 4. The barge is pushed to the wharf from a position of $100 \mathrm{~m}$ apart from the wharf is shown in Figure 5. 
Table 1: Main Dimension of The Barge.

\begin{tabular}{|l|l|}
\hline \multicolumn{2}{|c|}{$\mathbf{1 0 , 0 0 0}$ DWT Barge } \\
\hline Length Over All (LOA) & 122 meter $(\mathrm{m})$ \\
\hline Breadth $(\mathrm{B})$ & 28 meter $(\mathrm{m})$ \\
\hline Draught $(\mathrm{T})$ & 5.5 meter $(\mathrm{m})$ \\
\hline Coefficient Block $\left(\mathrm{C}_{\mathrm{B}}\right)$ & 0.91 \\
\hline Lateral Windage $\left(\mathrm{A}_{\mathrm{T}}\right)$ & 365 square meter $\left(\mathrm{m}^{2}\right)$ \\
\hline Longitudinal Windage $\left(\mathrm{A}_{\mathrm{L}}\right)$ & 1,263 square meter $\left(\mathrm{m}^{2}\right)$ \\
\hline
\end{tabular}

The availability of tugboats in the port is 5 (five) tugboats as shown in Table 2 .

Table 2: The Available Tugs.

\begin{tabular}{|l|c|c|c|c|c|}
\hline No & Power, (kW) & Length, (m) & Breadth, (m) & Draught, (m) & Bollard Pull, (t) \\
\hline 1 & $2 \times 1,300$ & 29 & 9.6 & 2.9 & 38 \\
\hline 2 & $2 \times 750$ & 30.6 & 8 & 2.6 & 22 \\
\hline 3 & $2 \times 870$ & 28.7 & 7.6 & 3.4 & 25 \\
\hline 4 & $2 \times 1,200$ & 31.1 & 10 & 3.7 & 35 \\
\hline 5 & $2 \times 1,200$ & 31.1 & 10 & 3.7 & 35 \\
\hline
\end{tabular}

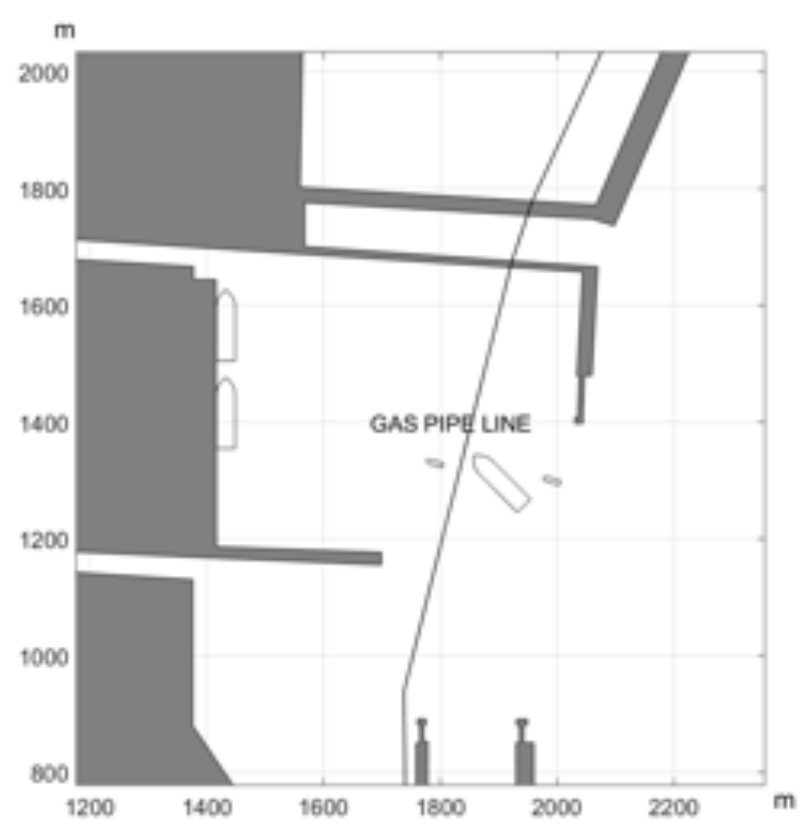

Figure 4: Towing and escorting. 


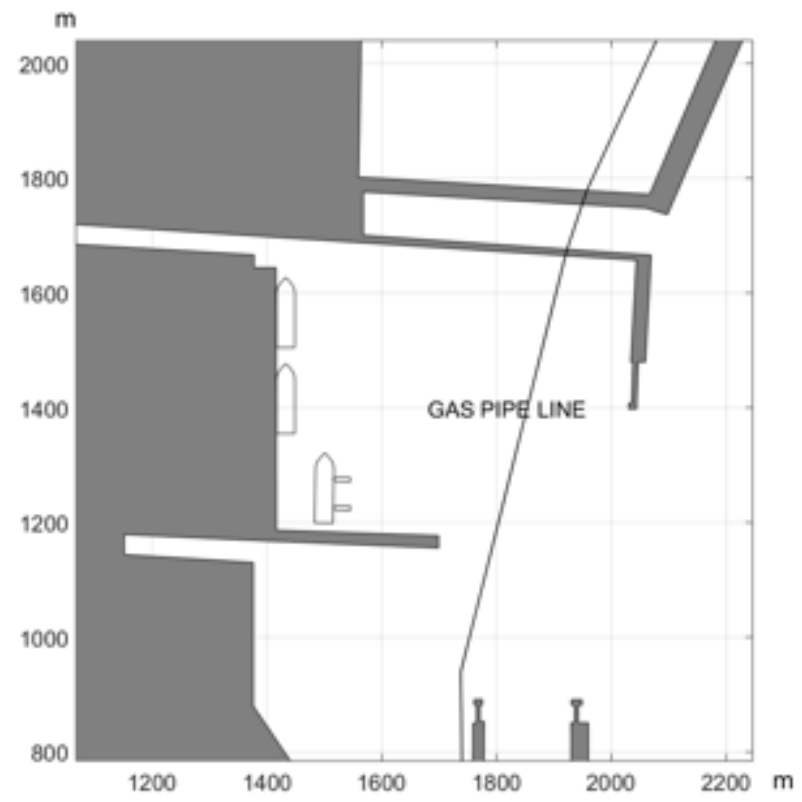

Figure 5: Lateral movement.

The simulation of berthing and unberthing of the third barge is shown in Figure 6 and Figure 7 . Figure 6 shows 2 (two) other barges have been berthed at the wharf. Both of the barges are assisted by two tugs with the capacity of $2 \times 21$ metric tons bollard pull. The third barge is assisted by tugs having capacity of $2 \times 35$ metric tons bollard pull. As shown by the figures of berthing and unberthing of Figures 4 and 5, a pivot maneuvers are needed to accomplish the maneuvering.

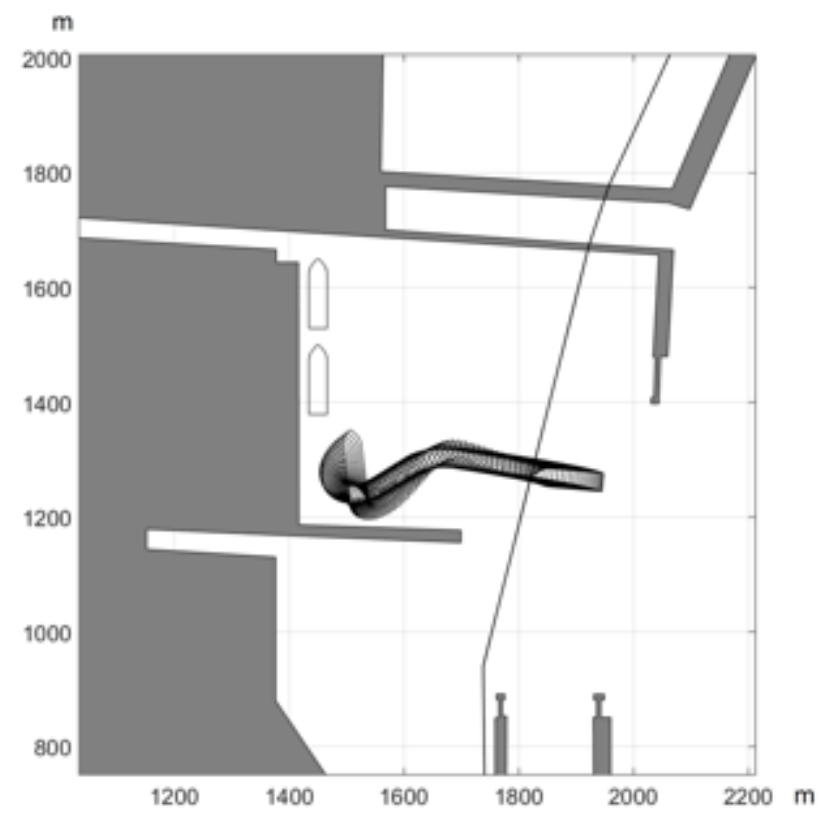

Figure 6: Berthing to position 3.

Unberthing maneuvers from position 1, 2, and 3 are presented by Figure 7, Figure 8, and Figure 9 , respectively. All of the maneuvers are assisted by two tugs with the capacity of $2 \times 21$ metric tons bollard pull. The figures show that the most difficult of the unberthing maneuver is the unberthing 
from position 3. The turning diameter of maneuver in Figure 9 is larger than the diameter in Figure 6.

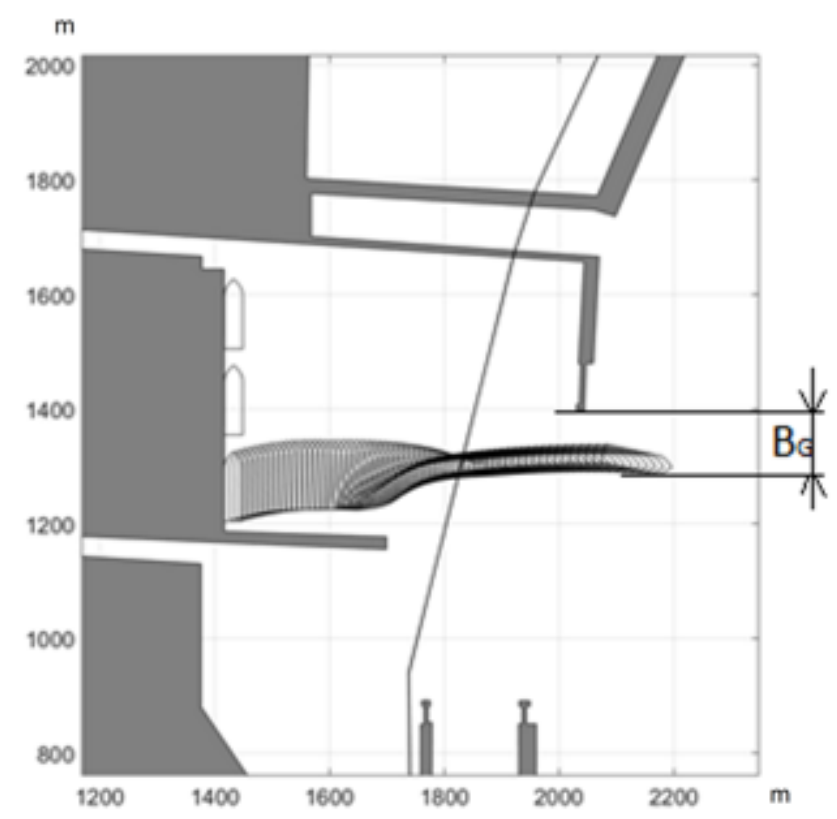

Figure 7: Unberthing from position 3.

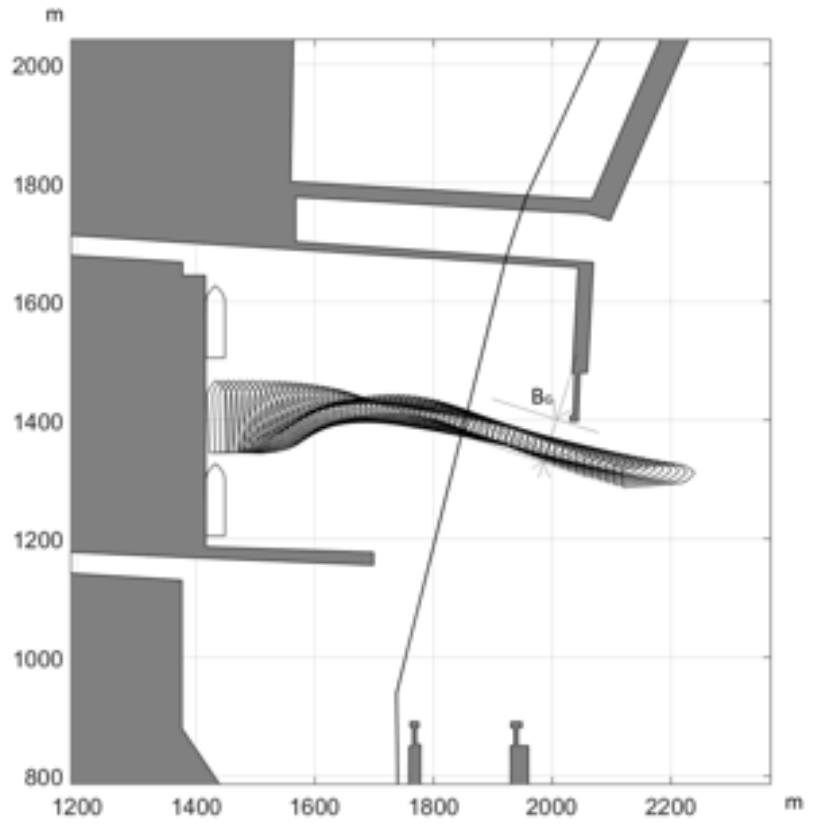

Figure 8: Unberthing from position 2. 


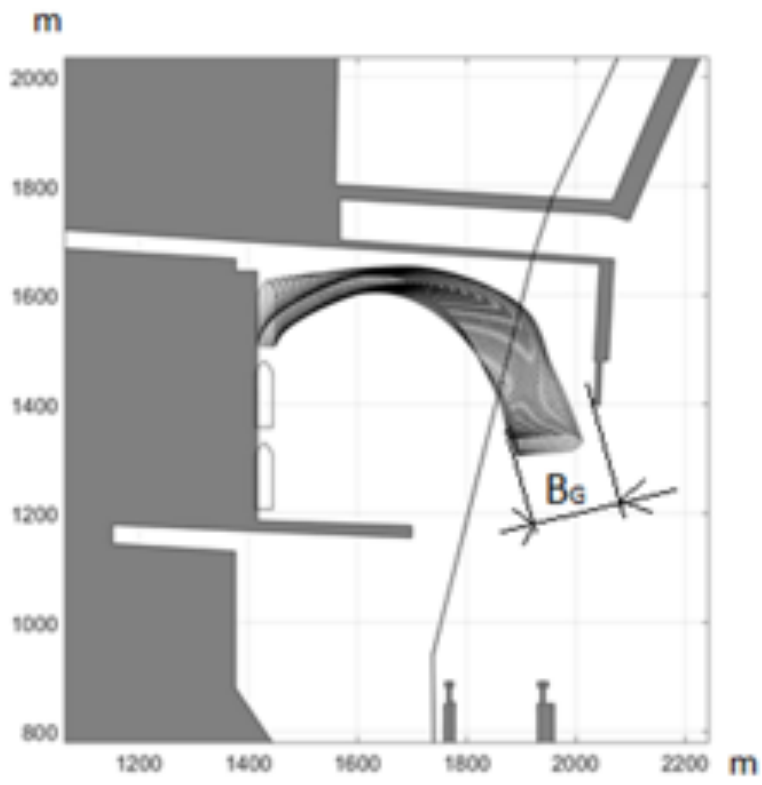

Figure 9: Unberthing from position 1.

The Environment Stress (ES) of the barge on berthing maneuver at the position of the basin entrance is 897 at the speed of 2 knots. This is a critical condition (more than 750 and less than 900). Figure 10 shows the 180 distances of obstacles barge entering the wharf with no other barge unberthing at the same time. The ES by moving speed is presented in Table 3 . The probability of ship to collide with the existing jetty for the unberthing maneuver from positions of 1,2 , and 3 is shown in Table 4.

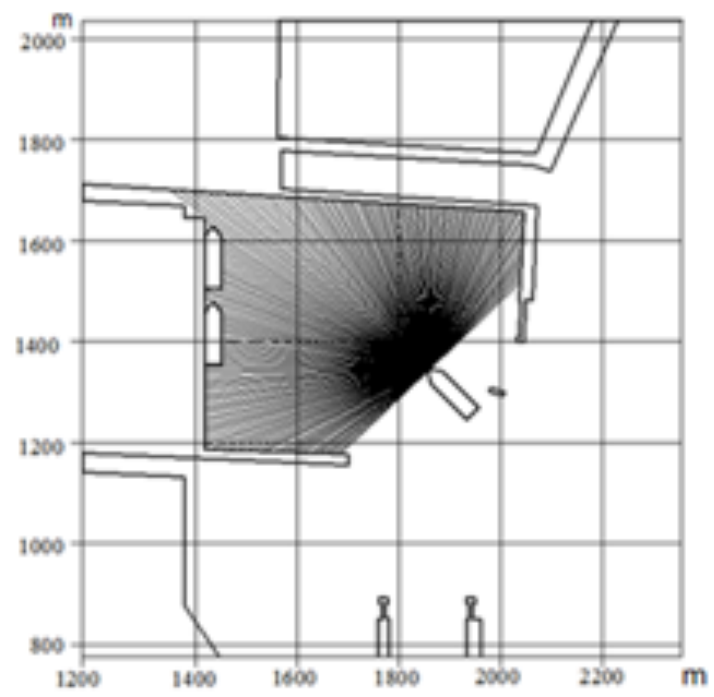

Figure 10: Distances to obstacles. 
Table 3. The ES by Barge Moving Speed

\begin{tabular}{|c|c|c|}
\hline No. & Moving Speed (knots) & Environment Stress \\
\hline 1 & 0.5 & 36 \\
\hline 2 & 1 & 537 \\
\hline 3 & 2 & 897 \\
\hline 4 & 3 & 1000 \\
\hline
\end{tabular}

Table 4. Geometric Collision Probability.

\begin{tabular}{|c|c|c|c|}
\hline No. & $\begin{array}{c}\text { Unberthing } \\
\text { Maneuver }\end{array}$ & $\begin{array}{c}\text { Geometric } \\
\text { Probability }\end{array}$ & $\begin{array}{c}\text { Collision } \\
\text { Probability }\end{array}$ \\
\hline 1 & From Position 3 & $\mathrm{~B} / \mathrm{B}_{\mathrm{G}}=0.50$ & $0.540 \times 10^{-4}$ \\
\hline 2 & From Position 2 & $\mathrm{~B} / \mathrm{B}_{\mathrm{G}}=0.55$ & $0.594 \times 10^{-4}$ \\
\hline 3 & From Position 1 & $\mathrm{~B} / \mathrm{B}_{\mathrm{G}}=0.85$ & $0.918 \times 10^{-4}$ \\
\hline
\end{tabular}

\section{Discussion}

The collision probability calculated based on Fujii model [7] depends on the causation probability of failing to avoid a collision and the probability of ship in a collision course. The collision probability model of Kristiansen [8] is the product of the probability of lossing navigational control and the conditional probability of having an accident given loss of vessel control. The causation probability which is the probability of lossing vessel control in the research area have been estimated by other researcher [7]. The conditional probabilty introduced by Kristiansen [8] is calculated based on the geometric of the area. This paper introduces a finding on the estimation of conditional probability which depends not only on the geometric of the area but also the maneuvering capability vessels in the area.

\section{Conclusions}

Based on the result of the study, it is concluded that the simulation of maneuvering using MMG model is not only be able to evaluate the capability of tugs to assist the berthing-unberthing maneuvers, but also to assess the collision probability. The capacity of tugs required for maneuvering in an area with the safety index of critical condition is higher than the minimum requirement of tugs capacity of the port authority.

\section{Acknowledgment}

The authors would like to acknowledge to the Laboratory of RAMS-ITS for supporting this study.

\section{References}

[1] http://beritatrans.com/2018/01/02/kemhub-sayangkan-insiden-kapal-mv-action-trader-tabrak-dermaga-di-gresik/

[2] Y. Yoshimura, and Y. Masumoto, "Hydrodynamic Database and Maneuvering Prediction Method with Medium High-Speed Merchant Ships and Fishing Vessels," International MARSIM Conference, Singapore 2012, pp. 1-9.

[3] H. Yasukawa, Y. Yoshimura, "Introduction of MMG standard method for ship maneuvering predictions," Journal of Marine Science and Technology, DOI 10.1007/s00773-014-0293-y, 2014. 
[4] T. Fujiwara, M. Ueno, and T. Nimura, "An Estimation Method of Wind Forces and Moments Acting on Ships," Mini Symposium on Prediction of Ship Maneuvering Performance, pp. 83-92, 2001

[5] K. Inoue, K. Masuda, W. Sera, "Guidelines to Assess the Safety of Marine Traffic-I. Evaluation of Ship-handling Difficulty based on the Environment Stress Model," The Journal of Japan Institute of Navigation, vol. 98, pp. 225233, 1997 (in Japanese).

[6] IPS Asmara, E. Kobayashi, N. Wakabayashi, KB Artana, AAB Dinariyana, and T. Pitana, "Traffic Safety Analysis in Madura Strait using MMG Model and AIS Data," Proceedings of the 5th International Maritime Conference on Design For Safety (IDFS), Shanghai China, DFS-2013-006, OS-1, 2013.

[7] Y. Mulyadi, E. Kobayashi, M. Wakabayashi, T. Pitana, Wahyudi, “Development of Ship Sinking Frequency Model Over Subsea Pipeline for Madura Strait Using AIS Data, “ WMU Journal of Maritime Affairs, vol. 13(1), pp. 5359, 2014.

[8] S. Kristiansen, Maritime Transportation; Safety management and Risk Analysis, Oxford: Elsevier ButterworthHeinemann, 2005. 